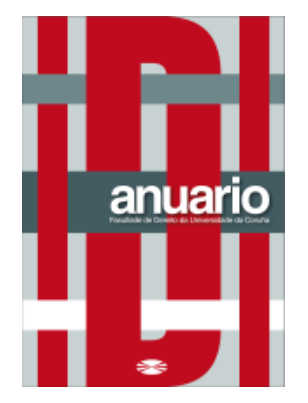

Anuario da Facultade de Dereito da Universidade da Coruña

Vol. 20 (2016), pp. 396-429

ISSNe: 2530-6324 || ISSN: 1138-039X

DOI: https://doi.org/10.17979/afdudc.2016.20.0.1951

\title{
REFLEXIONES SOBRE LA REGENERACIÓN DEMOCRÁTICA EN LA ADMINISTRACIÓN PÚBLICA
}

\author{
Jaime Rodríguez-Arana \\ Catedrático-Director del Grupo de Investigación de Derecho Público Global \\ Universidad de A Coruña
}

Fecha de recepción: 29.3.2016

Fecha de aceptación: 7.4.2016

Resumen: La regeneración democrática es hoy una asignatura pendiente del sistema político y administrativo en nuestro país. Para ello hay que abordar la dimensión ética del gobierno y la administración, la participación social en las políticas públicas, la transparencia y el acceso a la información y el gobierno abierto, así como el derecho fundamental de la persona a un buen gobierno y a una buena administración pública.

Palabras clave: Gobierno. Administración pública. Dignidad humana. Derecho a la buena administración y al buen gobierno. Transparencia. Gobierno abierto. Derechos fundamentales.

\begin{abstract}
Today, democratic regeneration is a pending issue in our country's political and administrative system. To tackle it, we need to address issues such as the government's ethical dimension, the administration, social participation in public policies, transparency and access to information and open government, as well as the fundamental right of people to good governance and good public administration.
\end{abstract}

Keywords: Governance. Public administration. Human dignity. The right to good administration and good governance. Transparency. Open government. Fundamental rights. 
SUMARIO: I. Introducción: Sobre la reforma administrativa. II. La centralidad del ciudadano. III. Participación ciudadana. IV. Transparencia y acceso a la información. V. El Gobierno abierto. VI. La buena Administración orientada al bien común. VII. La dimensión ética del personal al servicio de la Administración pública VIII. Códigos de Buen Gobierno. IX. Código Europeo de buena Conducta Administrativa. X. Reflexión conclusiva

\section{INTRODUCCIÓN.}

El problema de la legitimación democrática de la Administración pública siempre está en candelero. Porque, efectivamente, la Administración como tal no responde en el Parlamento. Porque sus funcionarios son seleccionados en teoría en rigurosos procesos objetivos sin participación ciudadana y, sobre todo, porque con el paso del tiempo advertimos un progresivo proceso de privatización del interés general y la emergencia de la llamada vetocracia, que pone en peligro ciertamente la esencia de la Administración pública en el Estado social y democrático de Derecho: el servicio objetivo al interés general. Por eso, desde hace tiempo se trabaja, con desigual fortuna según espacios y latitudes, en reformas y transformaciones de las estructuras, de los procedimientos y del personal al servicio de las Administraciones públicas. Y por eso, se intenta, de una u otra forma convertir el aparato burocrático a los principios y valores democráticos a través de esquemas y planteamientos que parten del pensamiento, abierto, plural, dinámico y compatible.

La centralidad del ciudadano y de sus derechos fundamentales, la apertura de la Administración a la realidad social, la motivación de las actuaciones públicas, las nuevas tecnologías y sólidos y exigentes reclamos de participación social, permiten entrever el calado y la magnitud de las transformaciones que deberían implementarse al corazón y estructura de nuestras Administraciones públicas, en exceso politizadas y en exceso pendientes de las formaciones políticas en detrimento de la racionalidad y objetividad que les impone la Carta Magna.

En efecto, la preocupación por los distintos procesos de lo que ha venido a denominarse reforma o modernización administrativa, esquemáticamente reforma del Estado, es constante a lo largo de los últimos tiempos, en los que se han sucedido intentos y propuestas para buscar la adecuación estructural y funcional de la Administración pública a la compleja y plural realidad en que vivimos.

Ahora, desde nuevas perspectivas, hemos que procurar construir una nueva Administración pública que deje en manos de los Gobiernos y Administraciones más cercanos a la población la principal carga de la tarea de ejecución y gestión administrativa residenciando en el ámbito estatal la sustancia de lo básico, de lo común, de lo que reclama, con pleno respeto la identidad propia, programaciones generales, normas que garanticen la igualdad esencial de todos los españoles en cualquier parte del territorio en que se encuentren. Por eso las políticas públicas de solidaridad y de equidad cada vez tienen una mayor proyección desde el Estado-nación. 
En términos generales, las transformaciones observadas en los países desarrollados desde la óptica de la gestión pública son bastante similares. Todo un conjunto de fenómenos como la preocupación por la eficacia pública, la búsqueda de la calidad en la prestación de los servicios públicos con la consiguiente orientación al ciudadano, supuestos de descentralización territorial y funcional, mayor participación de las organizaciones no gubernamentales en la gestión de servicios, etc., son intentos de reducir el exceso de leyes y reglamentos y, al tiempo, fórmulas para generar instrumentos que fortalezcan la idea de servicio público, tan necesaria hoy en día.

La práctica totalidad de los procesos de reforma y modernización administrativa se declaran dirigidos a conseguir una Administración Pública más eficaz, más sencilla, que cueste menos y que atienda mejor al ciudadano en sus necesidades públicas. De esta manera, se pone de manifiesto un dato de importancia capital: los modelos políticos y administrativos han de construirse a partir del ciudadano, de abajo hacia arriba, en función de sus necesidades colectivas. Este es, en mi opinión, el "punctum dolems" de cualquier proceso de reforma o modernización administrativa: que se tenga bien claro que el dueño, que el propietario de la Administración pública es el ciudadano. Sin embargo, siendo esta afirmación tan evidente, ha sido sistemáticamente preterida $\mathrm{y}$ orillada en los diferentes intentos de reforma $\mathrm{o}$ modernización realizados en los últimos años.

El Estado, de acuerdo con nuestra Constitución, se ha convertido en un Estado Social y Democrático de Derecho, superando anteriores concepciones basadas en una administración de autoridad, limitadora de los derechos fundamentales y libertades públicas. Aparece también en la Constitución el principio de eficacia como elemento rector de la actividad administrativa, al que es necesario unir, como derivación de la cláusula del Estado Social, el mandato constitucional dirigido a los poderes públicos de remoción de los obstáculos que impidan al individuo y los grupos en que se integra disfrutar real y efectivamente de la libertad y de la igualdad (artículo 9.2 CE). La eficacia debe ir siempre acompañada del servicio efectivo a los intereses generales. Si la eficacia se convierte en el criterio único de la acción administrativa, es muy fácil, y ejemplos hay, que se confundan los fines y los medios.

Insisto, los modelos políticos y administrativos deben construirse a partir de la persona $\mathrm{y}$ en función de sus necesidades colectivas, porque, como dispone nuestra Constitución, "la Administración sirve con objetividad los intereses generales y actúa de acuerdo con el principio de eficacia y descentralización, con sometimiento pleno a la Ley y al Derecho"(artículo 103.1 de la Constitución española de 1978). Además, el gasto público realizará una asignación equitativa de los recursos públicos y su programación y ejecución respondrán a los principios de eficiencia y economía (artículo 31.2 de la Constitución española de 1978), un artículo, por cierto, tan relevante como desconocido en la praxis pública y en la interpretación constitucional.

Los principios constitucionales de organización de la Administración española son, pues, los que han de proporcionarnos el marco general del proceso de reforma administrativa, que por su propia naturaleza es permanente y abierto mientras existan intereses generales que atender. 
La Administración pública del Estado Social y Democrático de Derecho ha de configurarse, pues, como una organización que debe distinguirse por los principios de legalidad, de eficacia y de servicio. Juridicidad, legalidad en sentido amplio, como gustaba decir a Hauriou, porque el procedimiento administrativo no es otra cosa que un camino pensado para salvaguardar los derechos e intereses legítimos de los ciudadanos. Eficacia, porque hoy es perfectamente exigible a la organización administrativa que se aplique a la consecución de los fines que se establecen. Y servicio, sobre todo, porque no se puede olvidar que la justificación de la existencia de la Administración pública como organización, se encuentra en el servicio a los intereses generales. Por eso, las distintas potestades y poderes públicos son manifestaciones concretas de esa idea de servicio a la comunidad, al pueblo. Legalidad, eficacia y servicio son, pues, los parámetros fundamentales de la acción administrativa.

Todo ello permite pensar en la necesidad de potenciar un clima de transformación permanente en la Administración pública, en el sentido de establecer las condiciones necesarias para su corrección y adaptación a unas circunstancias cambiantes de manera sistemática y cotidiana, aprovechando las opiniones de los ciudadanos sobre lo que, a su juicio, sería su funcionamiento deseable.

En esta situación, no puede ni debe olvidarse el actual, aunque permanente siempre, contexto de limitación del gasto público, que obliga a buscar un funcionamiento del aparato público que respete los indicadores de racionalidad en la gestión de recursos, tanto humanos como financieros, utilizando técnicas que van desde la programación por objetivos y el sistema de control de resultados a la introducción de estándares de calidad en los servicios públicos. Algo todavía, salvo en determinados caso, inédito entre nosotros, quizás por ese temor reverencial que se tienen a la introducción de indicadores "objetivos" como si de algo de otro mundo se tratara.

Por otra parte, la configuración del Estado social y democrático de derecho supone una nueva funcionalidad de la Administración Pública. En efecto, la Administración, al gestionar los intereses generales, no tiene que imponerse frente a los ciudadanos. Más bien debe propiciar fórmulas o medidas que impliquen la colaboración de la sociedad y, por tanto, de los ciudadanos en la elaboración de los criterios rectores que impulsen las políticas públicas. En otras palabras, la Administración pública ya no es dueña del interés público sino que está llamada, por su inserción en el Estado Social y Democrático de Derecho, a articular una adecuada intercomunicación con los agentes sociales para redefinir las políticas públicas. Quiere eso decir que los ciudadanos no deben ser sólo sujetos pasivos de las potestades públicas, sino que deben aspirar a ser legítimos colaboradores y protagonistas de la propia Administración para la gestión de los propios intereses que les afecten. Desde esta perspectiva puede entenderse mejor la función promocional de los poderes públicos en nuestro tiempo.

Una de las polémicas políticas más interesantes a las que podemos asistir en estos momentos es la de la función del Estado, y más concretamente, la de la supuesta crisis del llamado Estado del Bienestar. O lo que es lo mismo, la crisis de las "socialdemocracias" como consecuencia del ocaso de sus postulados más rutilantes y atractivos. 
¿Por qué ha entrado en crisis esta forma de entender las relaciones Estado-Sociedad?. Me parece que, entre otras razones, porque el Estado, que está al servicio del interés general y del bienestar general, se olvidó, y no pocas veces, de los problemas reales de la población.

Por eso, la reforma del Estado actual hace necesario colocar en el centro de la actividad pública la preocupación por las personas, por sus derechos, sus aspiraciones, sus expectativas, sus problemas, sus dificultades o sus ilusiones. El modelo del Estado intervencionista acabó por ser un fin en sí mismo, como el gasto público y la burocracia, que realmente no tienen sentido sino como instrumentos al servicio de los derechos y libertades de todos los ciudadanos. Hoy, más que nunca, repito, hay que recordar que el Estado es de la ciudadanía, que la burocracia es del pueblo y que los intereses generales deben definirse con la activa participación de los habitantes.

La reforma del Estado del Bienestar no puede depender de una ideología cerrada en la configuración de su proyecto porque las nuevas políticas se delimitan hoy por una renuncia expresa a todo dogmatismo político y por la apuesta hacia ese flexible dinamismo que acompaña a la realidad y, por ello, a los problemas de las personas. Hoy, me parece, la ideología cerrada aporta sobre todo y ante todo una configuración completa y cerrada de la realidad social y de la historia de carácter dogmática que no puede, es imposible, acercarse a un mundo que se define por su dinamismo, pluralismo y versatilidad.

Las prestaciones sociales, las atenciones sanitarias, las políticas educativas son bienes de carácter básico que un Gobierno debe poner entre sus prioridades políticas, de manera que la garantía de esos bienes se convierta en condición para que una sociedad libere energías que permitan su desarrollo y la conquista de nuevos espacios de libertad y de participación ciudadana.

Este conjunto de prestaciones del Estado, que constituye el entramado básico de lo que se denomina Estado de bienestar, no puede tomarse como un fin en sí mismo. Esta concepción se traduciría en una reducción del Estado al papel de suministrador de servicios, con lo que el ámbito público se convertiría en una rémora del desarrollo social, político, económico y cultural. Además, una concepción de este tipo se traduciría no en el equilibrio social necesario para la creación de una atmósfera adecuada para los desarrollos libres de los ciudadanos y de las asociaciones, sino que podría llevar a una concepción estática que privara al cuerpo social del dinamismo necesario para liberarse de la esclerosis y conservadurismo que acompaña a la mentalidad de los derechos adquiridos.

Las prestaciones, los derechos, tienen un carácter dinámico que no puede quedar a merced de mayorías clientelares, anquilosadas, sin proyecto vital, que puede llegar a convertirse en un cáncer de la vida social. Las prestaciones del Estado tienen su sentido en su finalidad.

Sírvanos como ejemplo la acción del Estado en relación con los colectivos más desfavorecidos, en los que -por motivos diferentes- contamos a los marginados, los parados, los pobres y los mayores. Las prestaciones del Estado nunca pueden tener la consideración de dádivas mecánicas. Más bien, el Estado debe proporcionar con sus prestaciones el desarrollo, la manifestación, el afloramiento de las energías y capacidades que se ven escondidas en esos 
amplios sectores sociales y que tendrá la manifestación adecuada en la aparición de la iniciativa individual y asociativa.

Un planteamiento de este tipo permitiría afirmar claramente la plena compatibilidad entre la esfera de los intereses de la empresa y de la justicia social, ya que las tareas de redistribución de la riqueza deben tener un carácter dinamizador de los sectores menos favorecidos, no conformador de ellos. Además, permitirá igualmente conciliar la necesidad de mantener los actuales niveles de bienestar y la necesidad de realizar ajustes en la priorización de las prestaciones, que se traduce en una mayor efectividad del esfuerzo redistributivo.

Las nuevas políticas públicas se configuran como puntos de encuentro entre la actuación pública y las aspiraciones, el sentir social, de la ciudadanía. Bien entendido que ese encuentro no puede ser resultado de una pura adaptabilidad camaleónica a las demandas sociales. Conducir las actuaciones políticas por las meras aspiraciones de los diversos sectores sociales, es caer directamente en otro tipo de pragmatismo y de tecnocracia: es sustituir a los gestores económicos por los prospectores sociales.

La prospección social, como conjunto de técnicas para conocer más adecuadamente los perfiles de la sociedad en sus diversos segmentos, es un factor más de apertura a la realidad. La correcta gestión económica es un elemento preciso de ese entramado complejo que denominamos eficiencia, pero ni una ni otra sustituyen al discurso político. La deliberación sobre los grandes principios, su explicitación en un proyecto político, su traducción en un programa de gobierno da sustancia política a las actuaciones concretas, que cobran sentido en el conjunto del programa, y con el impulso del proyecto.

Las políticas públicas modernas se hacen, pues, siempre a favor de las personas, de su autonomía -libertad y cooperación-, dándole cancha a quienes la ejercen e incitando o propiciando su ejercicio -libre- por parte de quienes tienen mayores dificultades para hacerlo. Acción social y libre iniciativa son realidades que el pensamiento compatible capta como integradoras de una realidad única, no como realidades contrapuestas.

Las políticas públicas modernas no se hacen pensando en una mayoría social, en un segmento social que garantice las mayorías necesarias en la política democrática, sino que las nuevas políticas se dirigen al conjunto de la sociedad, y cuando están verdaderamente centradas son capaces de concitar a la mayoría social, aquella mayoría natural de individuos que sitúan la libertad, la tolerancia y la solidaridad entre sus valores preferentes.

Conforme pasa el tiempo y contemplamos los dramas del siglo pasado, se ha ido perfilando con mayor claridad y se ha ido haciendo cada vez más explícita una idea que ha estado siempre presente de un modo u otro en el pensamiento democrático. El fundamento del Estado democrático hay que situarlo en la dignidad de la persona.

La persona se constituye en el centro de la acción pública. No la persona genérica o una universal naturaleza humana, sino la persona, cada individuo, revestido de sus peculiaridades irreductibles, de sus coordenadas vitales, existenciales, que lo convierten en algo irrepetible e intransferible, en persona. 
Cada persona es sujeto de una dignidad inalienable que se traduce en derechos también inalienables, los derechos humanos, que han ocupado, cada vez con mayor intensidad y extensión, la atención de los políticos democráticos de cualquier signo en todo el mundo.

En este contexto es donde se alumbran las nuevas políticas públicas, que pretenden significar que es en la persona singular en donde se pone el foco de la atención pública, que son cada mujer y cada hombre el centro de la acción política.

Este cambio en el sentido de la vida pública, cabría decir mejor, esta profundización en su significado, se ha producido a la par que una reflexión sobre el sentido y las bases del Estado democrático. Esta reflexión ha venido obligada no sólo por los profundos cambios a los que venimos asistiendo en nuestro tiempo. Cambios de orden geoestratégico que han modificado parece que definitivamente el marco ideológico en que se venía desenvolviendo el orden político vigente para poblaciones muy numerosas. Cambios tecnológicos que han producido una variación sin precedentes en las posibilidades y vías de comunicación humana, y que han abierto expectativas increíbles hace muy poco tiempo. Cambios en la percepción de la realidad, en la conciencia de amplísimas capas de la población que permiten a algunos augurar, sin riesgo excesivo, que nos encontramos en las puertas de un cambio de civilización.

Es una reflexión obligada también por la insatisfacción que se aprecia en los países desarrollados de occidente ante los modos de vida, las expectativas existenciales, las vivencias personales de libertad y participación.

Y es una reflexión que nos conduce derechamente a replantearnos el sentido de la vida y del sistema democrático, no para superarlo, sino para recuperarlo en su ser más genuino y despojarlo de las adherencias negativas con que determinados aspectos de las ideologías cerradas lo han contaminado, contaminaciones que han estado en el origen de las lamentables experiencias totalitarias de este siglo, particularmente en Europa.

Recuperar el pulso del Estado democrático y fortalecerlo, significa entre otras cosas, recuperar para el Estado los principios de su funcionalidad básica que se expresa adecuadamente -aunque no sólo- en aquellos derechos primarios sobre los que se asienta nuestra posibilidad de ser como hombres. Entre ellos el derecho a la vida, a la seguridad de nuestra existencia, el derecho a la salud.

En cualquier caso, debe quedar claro que esta transformación del modelo de Estado no afecta a los objetivos sociales planteados por el Estado del Bienestar, que incluso podrían ampliarse como consecuencia de una revisión del propio concepto de bienestar. Desde el informe BEVERIDGE (1942) hasta la actualidad, se adoptó un enfoque meramente negativo del bienestar, que consistía en luchar contra la indigencia, la enfermedad, la ignorancia, la miseria y la indolencia. Se trataba de una visión eminentemente económica del bienestar y de las prestaciones necesarias para su consecución. 
Hoy parece evidente la superación de esta visión. Las prestaciones o ventajas económicas no son casi nunca suficientes para producir bienestar; es además necesario promover simultáneamente mejoras psicológicas. Se trata, como apunta GUIDDENS, de alcanzar un bienestar positivo: en lugar de luchar contra la indigencia, se debe promover la autonomía; en vez de combatir la enfermedad, se debe prevenir su existencia promoviendo una salud activa; no hay que erradicar la ignorancia sino invertir en educación, no debe mitigarse la miseria, sino promover la prosperidad, y finalmente, no debe tratar de erradicarse la indolencia, sino premiar la iniciativa.

Por lo tanto, si el Estado tiene como función primaria genérica la promoción de la dignidad humana, se entenderá sin esfuerzo que el bienestar de los ciudadanos ocupe un lugar absolutamente prioritario en la actividad del Estado. Esto, forzoso es recordarlo, no es patrimonio exclusivo de ningún grupo ni de ninguna instancia política, es patrimonio del sentido común, o del sentir común. ¿Para qué querríamos un Estado que no nos proporcionará mejores condiciones para el desarrollo y el logro de los bienes que consideramos más apreciables por básicos?. Ciertamente hay todavía Estados concebidos como instrumentos de opresión o al servicio de los intereses de unos pocos, pero no podemos olvidar que nuestra referencia es el Estado democrático de Derecho, un Estado de libertades, que en la práctica y hasta ahora viene haciendo imposible tal situación de abuso entre nosotros.

Que el bienestar sea una condición para el desarrollo personal, como seres humanos en plenitud, no es un hallazgo reciente ni mucho menos. Ya los antiguos entendieron que sin unas condiciones materiales adecuadas no es posible el desarrollo de la vida moral, de la vida personal, y el hombre queda atrapado en la perentoriedad de los problemas derivados de lo que podríamos llamar su simple condición animal, y reducido a ella. Pero quisiera subrayar que bienestar no es equivalente a desarrollo personal. El bienestar es la base, la condición de partida que hace posible ese desarrollo. Por eso el bienestar no es un absoluto, un punto de llegada.

Concebir el bienestar como una finalidad de la política, como una meta o un punto de llegada, constituyen una espiral de consumo, de inversión pública, de intervención estatal, que llegó a desembocar en la concepción del Estado como providente, como tutor de los ciudadanos e instancia para la resolución última de sus demandas de todo orden. Este modo de entender la acción del Estado condujo de modo inequívoco a considerar a las instancias públicas como proveedoras de la solución a todas nuestras necesidades, incluso a las más menudas, incluso a nuestras incomodidades, incluso -si me apuraran- me atrevería a decir de los caprichos de muchos ciudadanos.

En esa espiral, asumida desde planteamientos doctrinarios que la historia más reciente ha demostrado errados, el Estado ha llegado prácticamente a su colapso, ha sido incapaz de responder a la voracidad de los consumidores que él mismo ha alumbrado y alimentado con mimo a veces demagógico. Exigencia de prestaciones y evasión de responsabilidades se han confabulado para hacer imposible el sueño socialista del Estado providencia. En un Estado así concebido el individuo se convierte en una pieza de la maquinaria de producción y en una unidad de consumo, y por ende se ve privado de sus derechos más elementales si no se somete a la lógica de este Estado, quedando arrumbados su libertad, su iniciativa, su 
espontaneidad, su creatividad, y reducida su condición a la de pieza uniforme en el engranaje social, con una libertad aparente reducida al ámbito de la privacidad.

Así las cosas, bien someramente descritas, la reforma del llamado Estado de Bienestar no ha sido tarea de un liberalismo rampante como algunos han pretendido hacer creer. No hay tal cosa. La necesidad de la reforma ha venido impuesta por una razón material y por una razón moral. La reforma del Estado de Bienestar ha sido una exigencia ineludible impuesta por el fracaso de una concepción desproporcionada. Dicho de otra manera, la reforma del Estado de Bienestar ha sido exigida por la realidad, por las cuentas, por su inviabilidad práctica. Y, en el orden moral, por la grave insatisfacción que se ha ido produciendo en las generaciones nuevas que han visto reducida su existencia -permítaseme la expresión- a una condición estabular que no podía menos que repugnarles.

Sentido tecnocrático de la política, podrán terciar algunos, reducción de los parámetros políticos a puras mediciones económicas, insistirán al oír hablar de cuentas. Realismo, sentido de la realidad, habrá que responder, sentido de la realidad que es una característica de las nuevas políticas públicas. Los castillos en el aire se vienen abajo, con grandes costes materiales y en medio de grandes frustraciones cuanto más portentosos hayan sido los castillos que quisimos construir. Porque uno de los fundamentos de cualquier proyecto vital -individual o colectivo-, no ciertamente el más importante, pero fundamento ineludible, es la viabilidad económica del proyecto. Y el Estado de Bienestar según la concepción de la socialdemocracia europea de hace unos años carecía de tal condición básica.

Afirmar que el Estado de Bienestar tal como lo concebía la socialdemocracia era inviable, afirmar que es necesaria la reforma de su estructura, que tal concepción presenta déficits insalvables en su mismo fundamento y articulación, no significa en absoluto anunciar que el bienestar es imposible o que debemos renunciar al bienestar. Hacerlo así supone enunciar una crítica roma, limitada y corta de las posiciones que expongo, y supone también, a mi juicio, instalarse en concepciones dogmáticas y consecuentemente maniqueas del Estado y de la sociedad. Equivaldría a afirmar que o el Estado de bienestar se establece conforme a una determinada fórmula -en este caso la socialista- o inevitablemente incumple su función.

Pues no es así. Denunciar el hecho comprobado de la inviabilidad del Estado de Bienestar, tal como se ha concebido históricamente por la socialdemocracia, reivindicar la necesidad y el proyecto político de las reformas necesarias, se hace en mi caso desde la convicción irrenunciable de que no sólo el bienestar público es posible, sino necesario, y no sólo necesario sino insuficiente en los parámetros en los que ahora se mide. Es decir, es necesario, -es de justicia-, que incrementemos los actuales niveles de bienestar -si se puede hablar así-, sobre todo para los sectores de población más desfavorecidos, más dependientes y más necesitados. Insisto, es una demanda irrebatible que nos hace el sentido más elemental de la justicia.

Sucede que no podemos caer de nuevo en la trampa en que cayeron los Estados providentes. Los sectores más desfavorecidos, los sectores más necesitados, son los más dependientes, y las prestaciones sociales del Estado no pueden contribuir a aumentar y agravar esa dependencia, convirtiendo, de hecho, a los ciudadanos en súbditos, en este caso del Estado, por muy impersonal que sea el soberano, o que tal vez por ser más impersonal y 
burocrático es más opresivo. En esta afirmación está implícita otra de las características de las nuevas políticas públicas: la finalidad de la acción política no es el bienestar, el bienestar es condición para la promoción de la libertad y participación de los ciudadanos, estas sí, auténticos fines de la acción política. Así el bienestar aparece como medio, y como tal medio, debe ser relativizado, puesto en relación al fin.

En efecto, el bienestar no sólo no está reñido con la austeridad, sino que no se puede ni concebir ni articular sin ella. Austeridad no puede entenderse como privación de lo necesario, sino como ajuste a lo necesario, y consecuentemente limitación de lo superfluo. Si no es posible realizar políticas austeras de bienestar no es posible implantar un bienestar social real, equitativo y progresivo, capaz de asumir -y para todos- las posibilidades cada vez de mayor alcance que las nuevas tecnologías ofrecen. Insisto en que austeridad no significa privación de lo necesario. Políticas de austeridad no significan por otra parte simplemente políticas de restricción presupuestaria. Políticas de austeridad significan, para mí, la implicación de los ciudadanos en el recorte de los gastos superfluos y en la reordenación del gasto. Sin la participación activa y consciente de una inmensa mayoría de los ciudadanos considero que es imposible la aproximación al Estado de bienestar social que todos -de una manera o de otra anhelamos-. Es necesaria por parte de la ciudadanía la asunción de la responsabilidad política en su conducta particular, para hacer posible la solidaridad, la participación, que es meta de la acción política.

En este sentido, las políticas austeras son compatibles con una expansión del gasto. Porque la expansión del gasto es necesaria, porque no son satisfactorios aún los niveles de solidaridad efectiva que hemos conseguido. Pero expandir el gasto sin racionalizarlo adecuadamente, sin mejorar las prioridades, sin satisfacer demandas justas y elementales de los consumidores, es hacer una contribución al despilfarro. Y aquí no me detengo en una consideración moralista de la inconveniencia del gasto superfluo, sino que me permito reclamar y que se comprenda la tremenda injusticia que está implícita en el gasto superfluo o irracional cuando hay tantas necesidades perentorias sin atender todavía. El problema de la crisis actual, consecuencia de la irresponsabilidad de gobernantes y de la obsesión por el lucro de no pocos dirigentes financieros, impide, en este momento, salir de la austeridad. Pero tiempos vendrán, más pronto que tarde, en que volveremos a recuperar el paso.

\section{LA CENTRALIDAD DEL CIUDADANO.}

Una de las cuestiones de mayor calado que tiene planteada las ciencias sociales se refiere al papel de los ciudadanos en el entramado político-social en que nos ha tocado vivir. Es verdad que en un sistema democrático el gobierno es del pueblo y se realiza para y por el pueblo. Siendo esta afirmación incontestable, la centralidad de la persona, del ser humano, del ciudadano es, pues, indudable.

En efecto, el poder público es de los ciudadanos. El titular de los poderes del Estado es el pueblo soberano, que encomienda a los actores públicos el ejercicio, la gestión, del poder, de forma y manera que quien lo administra en nombre de la comunidad debe permanentemente rendir cuentas de su ejercicio. 
Los ciudadanos, pues, tienen una función bien relevante en la definición, análisis, implementación, ejecución y evaluación de las políticas públicas. Han dejado de ser sujetos inertes que pasivamente recibían servicios y prestaciones públicas. Ahora, en el Estado social y democrático de Derecho, deben ser protagonistas, sujetos activos, personas que participan en la determinación y configuración del interés general.

Una de las cuestiones que más preocupa a los profesores e investigadores de las ciencias sociales es, sin lugar a dudas, la fuerza y operatividad de las iniciativas civiles, el protagonismo de las personas en las nuevas políticas públicas. Así, se ha llamado la atención sobre el déficit de la presencia activa y potente de una ciudadanía reflexiva, dispuesta a hacer valer en todo momento la evidencia de que la única configuración justa de una sociedad es aquella que reconoce la relevancia pública de la libertad concertada de sus miembros. En este sentido, las profecías de TOCQUEVILLE sobre el llamado "despotismo blando" o sobre el sometimiento de las personas y comunidades solidarias a ese "inmenso poder tutelar" se han ido cumpliendo casi a la letra.

Colocar a las personas en el centro de la acción pública, conduce a una disposición de prestar servicios reales a los ciudadanos, de servir a sus intereses reales. En este sentido, el entendimiento con los diversos interlocutores es posible partiendo del supuesto de un objetivo común: libertad y participación.

La importancia de los logros concretos, los resultados constatables -sociales, culturales, económicos,..- en la actividad pública, no derivan de la importancia del éxito del agente público, sino de las necesidades reales de las personas que, viéndose satisfechas, permiten alcanzar una condición de vida que posibilita el acceso a una más plena condición humana.

Una más profunda libertad, una más genuina participación son el fruto de lo que se debe promover desde las instancias públicas. Porque no debemos olvidar que las cualidades de la persona no tienen un carácter absoluto. El hombre no es libre a priori, si se puede hablar así; la libertad de los hombres no se nos presenta como una condición preestablecida, como un postulado, sino que la libertad se conquista, se acrisola, se perfecciona en su ejercicio, en las opciones y en las acciones que cada hombre y cada mujer empieza y culmina.

Las recientes transformaciones en el orden conceptual, metodológico y práctico que están poniendo en tela de juicio muchas convicciones y formas de entender la realidad pública, ayudan a profundizar en uno de los pilares básicos del pensamiento democrático: la relación de los ciudadanos con el poder público.

Los Poderes públicos, las Administraciones públicas, son de los ciudadanos, de las personas, que deben tomar mayor conciencia de su posición central en el sistema político Entonces, quienes trabajan en el sector público no son, ni más ni menos, que gestores de intereses ajenos que deben rendir cuentas periódicamente de su administración.

El ciudadano, la persona, es el centro del sistema, y, por ello, el poder público no debe ejercerse nunca desde la perspectiva de los privilegios o las prerrogativas, sino como un instrumento de servicio a la entera sociedad. La Constitución española de 1978 dispone en el 
artículo 103 que la Administración pública sirve con objetividad los intereses generales.

El Estado social y democrático de Derecho otorga una posición jurídica a la persona, un estatus de ciudadano en sus relaciones con el Poder público. En efecto, ahora los ciudadanos ya no son sujetos inertes, simples receptores de bienes y servicios públicos; son protagonistas principales de los asuntos de interés general, hasta tal punto de que son los legítimos dueños del poder público y de sus estructuras y, por tanto, disponen de una serie de derechos, siendo el fundamental el derecho a una buena administración pública.

En este sentido, el Poder público en sus diferentes dimensiones territoriales y funcionales, está al servicio de la persona atendiendo las necesidades públicas en forma continua y permanente. Esta es la clave del sistema democrático y, por ende, reclama la construcción de un nuevo estatuto del ciudadano en relación con el Poder público en el que sus derechos estén reconocidos expresamente. A partir de ahí será más fácil que el propio ciudadano tome mayor conciencia de su posición central en el sistema y reclame y reivindique servicios públicos de calidad.

Los poderes del Estado derivan del consentimiento de los ciudadanos, que son sus titulares, debiéndose buscar un equilibrio entre dichos poderes como entre derechos y deberes de las personas. En su representación, legisladores, ejecutivos y jueces ejercen el poder que les corresponde. Como administradores y gestores de estos poderes del Estado, deben rendir cuenta permanentemente de su ejercicio ante toda la ciudadanía a través de los diferentes mecanismos que los Ordenamientos jurídicos nacionales establecen.

En el marco del complejo Gobierno-Administración pública, núcleo en el que se realiza la definición e implementación de las políticas públicas propias del Poder ejecutivo, ha ido cobrando especial relieve en los últimos tiempos la obligación de proceder a una buena administración pública, aquella que se dirige a la mejora integral de las condiciones de vida de las personas. La buena administración pública es, pues, una obligación inherente a los poderes públicos y se caracteriza sobremanera porque el quehacer público promueva los derechos fundamentales de las personas de forma que las actuaciones administrativas armonicen criterios de objetividad, imparcialidad, justicia y equidad y sean prestadas en un plazo razonable.

Desde la perspectiva de la centralidad del ser humano, principio y fin del Estado, el interés general debe estar administrado de tal forma que en su ejercicio las diferentes Administraciones públicas hagan posible el libre y solidario desarrollo de cada persona en sociedad. Es decir, hace a la condición de la persona, es inherente al ser humano, que el gobierno y la administración del interés general se realice en forma que sobresalga su dignidad y todos sus derechos fundamentales, tanto los individuales como los sociales.

\section{PARTICIPACIÓN CIUDADANA}

La participación, una de las grandes directrices políticas de la arquitectura constitucional del Estado social y democrático de Derecho, está prevista en el artículo 9.2 de 
la Constitución española de 1978, que manda a los Poderes públicos facilitar la participación de todos los ciudadanos en la vida política, económica, cultural y social.

En un mundo en el que la exaltación del poder y del dinero ha superado todas las cotas posibles es menester recordar que la dignidad de todo ser humano, cualquiera que sea su situación, es la base del Estado de Derecho y, por ende, de las políticas públicas que se realizan en los modelos democráticos. La ausencia de la persona, del ciudadano, de las políticas públicas, explica que a pesar de tantas normas promotoras de esquemas de participación como se promulgan o se dictan, ésta se haya reducido generalmente a un recurso retórico, demagógico, sin vida, sin presencia real, pues la legislación no produce mecánica y automáticamente la participación.

La participación no es sólo una consecuencia de entender el interés general en un Estado social y democrático de Derecho como un concepto que debe definirse a través de una acción concertada entre Poderes públicos y agentes sociales. Significa, además de un objetivo político sentado en la Constitución, un método de trabajo social dirigido a que los asuntos de interés general estén transidos de presencia social en todas sus dimensiones y aspectos. La políticas públicas democráticas deben colocar en el centro de su elaboración, implementación, ejecución y evaluación, a las personas destinatarias de dichas actuaciones del poder público.

En sentido negativo, las políticas públicas democráticas no pueden atender tan sólo los intereses de un sector, de un grupo, de un segmento social, económico o institucional, ya que una condición básica de estas políticas públicas es el equilibrio, entendiendo por tal, la atención a los intereses de todos y cada uno de los ciudadanos en cuantos miembros de la comunidad. Atender públicamente el interés de algunos, aunque se trate de grupos mayoritarios, significa prescindir de otros, y consecuentemente practicar un exclusivismo que es ajeno al entendimiento democrático de la participación.

La determinación de los objetivos de las políticas públicas no puede hacerse realmente si no es desde la participación ciudadana. La participación ciudadana se configura, pues, como un objetivo público de primer orden, ya que constituye la esencia misma de la democracia. Una actuación política que no persiga, que no procure un grado más alto de participación ciudadana, no contribuye al enriquecimiento de la vida democrática y se hace, por lo tanto, en detrimento de los mismos ciudadanos a los que se pretende servir. Pero la participación no se formula solamente como objetivo, sino que las exige la práctica de la participación como método.

En efecto, tratar la participación como método es hablar de la apertura de la organización pública que la quiere practicar, hacia la sociedad. Una organización pública cerrada, vuelta sobre sí misma, no puede pretender captar, representar o servir los intereses propios de la ciudadanía, de las personas a que debe atender objetivamente. La primera condición de esa apertura es una actitud, una disposición, alejada de la suficiencia y de la prepotencia, propias tanto de las formulaciones propias de las ideologías cerradas como de las tecnocráticas $\mathrm{o}$ burocratizadas. Pero las actitudes $\mathrm{y}$ las disposiciones necesitan instrumentarse, traducirse en procesos y en instrumentos que las hagan reales. Y la primera instrumentación que exige una disposición abierta es la comunicativa, la comunicación. 
Las reformas en esta materia deben traducirse en estar receptivos, tener la sensibilidad suficiente para captar las preocupaciones e intereses de la sociedad en sus diversos sectores y grupos, en los individuos y colectividades que la integran. Pero no se trata simplemente de apreciaciones globales, de percepciones intuitivas, ni siquiera simplemente de estudios o conclusiones sociométricas. Todos esos elementos y otros posibles son recomendables y hasta precisos, pero la conexión real con los ciudadanos, con los vecinos, con las personas, exige diálogo real. Y diálogo real significa interlocutores reales, concretos, que son los que encarnan las preocupaciones y las ilusiones concretas, las reales.

En la libre participación de los ciudadanos en los asuntos de interés general se encuentra un elemento central de la vida individual y social de los hombres y de las mujeres, un elemento que contribuye a definir y realizar los objetivos del Estado social y democrático de Derecho. La participación, en efecto, supone el reconocimiento de la dimensión social de la persona, la constatación de que sus intereses, sus aspiraciones, sus preocupaciones trascienden el ámbito individual o familiar y se extienden a toda la sociedad en su conjunto.

Frente a la participación como un absoluto, tal como se pretende desde algunas concepciones organicistas de la sociedad, la participación en un Estado social y democrático de Derecho debe ser libre. La referencia a la libertad remite a una condición irrenunciable de su participación, su carácter libre, pues sin libertad no hay participación. La participación no es un suceso, ni un proceso mecánico, ni una fórmula para la organización de la vida social. La participación, aunque sea también todo eso, es más: significa la integración del individuo en la vida social, la dimensión activa de su presencia en la sociedad, la posibilidad de desarrollo de las dimensiones sociales del individuo, el protagonismo singularizado de todos los hombres y mujeres.

La crisis a la que hoy asisten las democracias, o más genéricamente nuestras sociedades, en las que se habla a veces de una insatisfacción incluso profunda ante el distanciamiento que se produce entre lo que se llama vida oficial y vida real, manifestada en síntomas variados, exige una regeneración permanente de la vida democrática porque ésta significa ante todo, la acción y el protagonismo de los ciudadanos, la participación.

Sin embargo, frente a la perspectiva de la participación centrada exclusivamente en los mecanismos políticos de decisión, debe ser entendida de un modo más general, como protagonismo civil de los ciudadanos, como participación cívica, como participación ciudadana.

\section{TRANSPARENCIA Y ACCESO A LA INFORMACIÓN}

La transparencia en los Gobiernos y Administraciones públicas es, desde luego, uno de los principales desafíos del buen gobierno y de la buena administración. Por una parte, porque la transparencia es una exigencia de calidad democrática $\mathrm{y}$, por otra, porque el derecho fundamental ciudadano a una buena administración incluye expresamente el derecho 
de los ciudadanos a que Gobiernos y Administraciones públicas, estatales, autonómicos y locales, sean transparentes en su actividad y en la forma en que implementan las políticas públicas.

En democracia, los poderes del Estado residen en el pueblo y se realizan por y para el pueblo. El pueblo es el soberano y encomienda la gestión y administración de lo público a unos representantes que tienen la obligación de dar cuentas de su gestión y administración a la ciudadanía en forma constante, transparente y argumentada. El gobierno y la administración del espacio público deben servir con objetividad el interés general promoviendo las condiciones precisas para el libre y solidario ejercicio de los derechos fundamentales por parte de todas las personas.

La transparencia es, debe ser, un hábito propio que ha de presidir la actuación de los diferentes Entes públicos y, por ello, de las personas físicas que en ellos laboran. También, por supuesto, debe regir la actuación de todas las organizaciones e instituciones que realizan actividades de interés general o que utilicen o manejen fondos públicos en sus actividades. Por una razón bien sencilla: como el pueblo es el dueño y señor, el soberano, de los fondos públicos, es lógico que todos los organismos y organizaciones que administren estos recursos, sean Administraciones, partidos, sindicatos, patronales o, entre otros, ONGs, concesionarios de servicios públicos o cualesquiera otra forma de organización que reciba dinero público, se rijan por la publicidad y la concurrencia en materia contractual, y por el mérito y la capacidad en la selección de personal.

Efectivamente, los fondos públicos requieren, por su propia naturaleza, uso transparente y publicidad. Por eso, los procesos de selección de personal que se realizan siempre que hay fondos públicos de por medio, han de estar regidos por los principios de mérito y capacidad. Igualmente, cuándo se trata de contratar bienes o servicios, el carácter público de esos fondos, reclama siempre publicidad y concurrencia.

En el mismo sentido, las instituciones que realizan tareas de interés general también deben guiar su actuación en materia de personal y de contratos a estos criterios. No hacerlo así, encastillarse en la oscuridad y en la opacidad, no es más que una manifestación de arbitrariedad incompatible con los postulados del Estado de Derecho. Tiempo atrás John LOCKE enseñó que en toda manifestación de arbitrariedad hay siempre irracionalidad, subjetividad, propiedades del absolutismo bien opuestas a lo que debe ser el régimen y funcionamiento de los gobiernos y administraciones públicas de un Estado social y democrático de Derecho.

En este contexto, la transparencia y el acceso a la información de interés general deben ser gestionados o administrados por un órgano colegiado de naturaleza plural, en el que estén representados los Poderes públicos así como la sociedad civil. Es lógico que así sea porque el pluralismo es también una cualidad democrática que debe estar presente en todas aquellas cuestiones que afectan a la rectoría de asuntos de tanta envergadura como la gestión de la transparencia o del interés general.

La actual ley española de transparencia, de diciembre de 2013 se dirige, según lo dispuesto en su artículo 1, a ampliar y reforzar la transparencia de la actividad pública y a 
reconocer y garantizar el derecho a la información. Ampliar significa que la luz y los taquígrafos tengan más potencia e intensidad: abrir a la transparencia a actividades hasta ahora oscuras u opacas. Y reforzar alude a hacer más fuerte e intensa la obligación de los Entes públicos de mostrar a la ciudadanía cómo y de qué forma se gestiona lo que es del común.

El derecho fundamental de todo ciudadano europeo a la buena Administración, recogido en el artículo 41 dela Carta de los Derechos Fundamentales de la Unión Europea de diciembre de 2000 fue formulado para salir al paso, para reaccionar frente a la denominada, por el Defensor del Pueblo Europeo, mala administración pública. Mala administración que viene caracterizando desde hace unos años a numerosas administraciones y gobiernos del área europea y que mucho tiene que ver con la escasa transparencia y publicidad reinante al interior de tantas instituciones y organismos públicos en el espacio europeo.

La conformación como derecho fundamental de la buena administración pública es una relevante manera de subrayar el papel central del ciudadano en todo lo referente al manejo y conducción de los asuntos relativos al interés general. Tal derecho es configurado por la Carta Europea en atención a la equidad, a la imparcialidad a la responsabilidad, a la transparencia y al plazo razonable en la resolución de los expedientes. Por tanto, la administración parcial, inequitativa, opaca, irresponsable y lenta es, a tenor de lo consignado en este precepto de la Carta, mala administración.

Transparencia Internacional (TI) acaba de publicar el informe mundial sobre la percepción de la corrupción correspondiente a 2014. España, se mantiene en el puesto 37 de entre 175 países. En Europa nos superan Grecia e Italia y si se hiciera un ranking de los 30 países europeos, ocuparíamos el lugar 19. Encabeza el ranking general Dinamarca, y la siguen Nueva Zelanda, Finlandia, Suecia, Noruega y Singapur. A la cola de nuevo Eritrea, Libia, Uzbekistan, Irak, Corea del Norte, Sudán, Afganistán, y Somalia.

El acceso del pueblo, de todos y cada uno de los ciudadanos, a los asuntos de interés general, constituye una de las manifestaciones más relevantes de la centralidad que la persona humana tiene en el sistema democrático. Además, en estos casos, nos hallamos ante un derecho subjetivo, de gran relieve, a obtener información en relación con los asuntos de interés general. En realidad, este derecho fundamental es un corolario necesario del principio básico de la democracia: el poder es del pueblo, los ciudadanos son sus titulares. Los poderes públicos, desde este punto de vista, no son más, ni menos, que instituciones de la comunidad a la que han de rendir cuentas periódicamente de forma argumentada y razonada.

\section{EL GOBIERNO ABIERTO.}

Uno de los aspectos centrales de la reforma y modernización del Gobierno y de la Administración pública en nuestros días se refiere, como es bien conocido, al gobierno en red, al gobierno abierto, al gobierno y a la administración transparente. Una forma de gobierno y administración pública en la que las nuevas tecnologías permiten subrayar la centralidad del ciudadano en las políticas públicas. En efecto, en casi todos los países 
desarrollados se han acometido, con distinta suerte, procesos de implantación de las nuevas tecnologías en el marco de las nuevas políticas públicas a implantar.

Tal y como se define en el Memorándum del Presidente Obama de 21 de enero de 2009 sobre transparencia y el gobierno en red, tal forma de entender la función gubernamental ha de estar caracterizada por el aseguramiento de la confianza pública a partir de un sistema de transparencia, participación pública y colaboración. Por tanto, los tres principios del gobierno abierto son la transparencia, la colaboración horizontal y vertical y la participación pública en el diseño y ejecución de las políticas públicas.

El gobierno abierto tiene un objetivo esencial y dos objetivos básicos. El objetivo esencial es la apertura del gobierno y de la administración pública. Deben abrirse a la sociedad, a los ciudadanos, a las empresas y a las organizaciones en general. El primer objetivo básico es de orden político: fortalecer la democracia y el segundo de naturaleza administrativa, promover la eficacia y la eficiencia en las tareas de naturaleza ejecutiva o administrativa.

El gobierno abierto es consecuencia del eGovernment o gobierno electrónico. Es decir, es una proyección de la irrupción de Internet como red de redes en la sociedades occidentales a mediados de los noventa del siglo pasado, una irrupción, como señala GARCIA MEXIA, que al ocupar todas las facetas de la vida humana, no podía dejar de tener reflejo en la esfera pública.

En Europa el Gobierno y la Administración electrónica empezaron a plantearse a partir de tres relevantes documentos. El primero, el informe Bangemann (Europa y la sociedad global de la información), de 1994, que subraya por encima de todo los ahorros en costes de esta forma de realizar el gobierno y la administración pública. El segundo y tercero son las Recomendaciones del Consejo de Europa de 15 de diciembre de 1994 y de 30 de septiembre también de 1994. La de 15 de diciembre se refiere a la gobernanza electrónica y la de 30 de septiembre a los estándares legales, procedimentales y técnicos de los sistemas de votación electrónica. Más adelante, el 18 de febrero de 2009, la Recomendación del Consejo de Europa sobre democracia electrónica da un paso más hacia una más abierta forma de gobierno y gestión democrática.

Estos documentos, junto a las iniciativas europeas e-Europe 2002, e-Europe 2005 y estrategia i2010, nos conducen a la Agenda Digital para Europa 2010 en la que la Comisión Europea propone una serie de orientaciones estratégicas sobre administración electrónica, encabezadas por la necesidad de desarrollar y desplegar servicios públicos transfronterizos en línea.

En España estas consideraciones se concretan en la Agenda Digital para España 2013 que propone una mejora de la administración electrónica y de los servicios públicos digitales. Según el United Nations E-Government España ocupa en materia de gobierno electrónico el puesto 23 de entre 193 Estados y es uno de los tres líderes emergentes junto a Austria e Islandia. 
El gobierno abierto constituye un estadio de la evolución natural del gobierno electrónico aunque realmente, además de estar conectado al eGovernment, esta forma de concebir el gobierno y la administración pública está más cercana a las modernas concepciones del buen gobierno y de la buena administración, que además de una obligación inherente a los Poderes públicos, son también un principio de organización y actuación pública y, sobre todo, un derecho fundamental de los ciudadanos.

El eGovernment es consecuencia de los procesos de reforma y modernización del Estado de finales del siglo pasado presididos por la globalización y la tecnificación a partir de cuatro estrategias: financieras (menores costes), de crecimiento (mejores servicios), de eficiencia (optimizar procesos) y de proximidad al ciudadano.

Otra perspectiva del eGovernment sería la de constituir un medio para una buena gobernanza, un gobierno caracterizado por la transparencia, la participación y la rendición de cuentas. El gobierno abierto, tal y como ha señalado GARCIA MEXIA, se ha convertido en una especie de "mecanismo-puente" entre la dimensión ética de la función pública y las nuevas tecnologías en el desarrollo de las tareas del gobierno y la administración pública. Ética y nuevas tecnologías son dos dimensiones del gobierno y la administración pública que deben ir inseparablemente unidas para que se pueda hablar con propiedad de gobierno abierto. Las TICs se justifican en este campo en la medida en que abran el gobierno y la administración a los ciudadanos de manera que éstos se consideren los auténticos soberanos del sistema político. Entonces, la accesibilidad y la transparencia facilitan la democracia entendida como el gobierno del pueblo, por el pueblo y para el pueblo. A partir de ahí surge una mayor participación y entonces se comprende en su pleno sentido que el interés general no debe ser definido unilateralmente por el gobierno o la administración pública sino a través de inteligentes alianzas entre Poder público y agentes sociales.

En la medida en que el Gobierno y la Administración pública se asientan sobre la ética y las nuevas tecnologías, entonces, en expresión inglesa, el gobierno abierto forma parte del paisaje constitucional y puede ser asumido por todos, ya sean gobiernos, ciudadanos, o empresas u organizaciones de un color o de otro. Este es el principal sentido del gobierno abierto en la tradición del gobierno electrónico y los valores que componen la dimensión ética de la función y el servicio público.

La transparencia se concreta en la apertura de datos e información en manos del poder público gracias al empleo de Internet y las TIC (Open data). La participación se materializa en herramientas y en democracia electrónica a través de las redes sociales y otros mecanismos 2.0, así como en asambleas y encuentros off-line con los propios ciudadanos. Y la colaboración se proyecta en sitios web donde los ciudadanos aportan sus conocimientos para la elaboración de políticas públicas.

El Open data constituye el mecanismo de menor interacción pues el ciudadano se limita a recibir las informaciones suministradas por el poder público. La participación, por su parte, incrementa la interacción con el ciudadano, a quien se solicitan decisiones (votación electrónica) y opiniones (redes sociales o foros off-line). La colaboración incrementa el compromiso cívico pues en este caso el ciudadano en este caso aporta el propio conocimiento como bagaje personal. 


\section{LA BUENA ADMINISTRACIÓN ORIENTADA AL BIEN COMÚN.}

La buena Administración pública es un derecho de los ciudadanos a que los Poderes públicos sin excepción resuelvan los asuntos de interés general de forma justa, equitativa, objetiva y en plazo razonable promoviendo constantemente la dignidad humana. Además, es una obligación inherente a la esencia de los Poderes públicos y un principio de actuación administrativa. Los ciudadanos, pues, tienen derecho a exigir tales características de objetividad, imparcialidad, justicia, equidad y resolución en plazo razonable en el funcionamiento y actividad de todas las Administraciones públicas determinados patrones o estándares de calidad en el funcionamiento de la Administración.

El derecho, principio, y obligación de la buena Administración pública vincula la forma en que se deben dirigir las instituciones públicas en una democracia avanzada. Dirigir en el marco de la buena Administración pública supone asumir que la Administración pública, existe y se justifica, en la medida en que ésta, como dispone el artículo 103 de nuestra Constitución, sirve objetivamente al interés general.

Las instituciones públicas en la democracia no son de propiedad de sus dirigentes, son del pueblo que es el titular de la soberanía. El responsable público tiene que saber, y practicar en consecuencia, que la buena Administración pública le obliga a rendir cuentas continuamente a la ciudadanía y a que la búsqueda de la calidad en el servicio público presida toda su actuación

El artículo 41 de la Carta Europea de los Derechos Fundamentales, aprobada en Niza en diciembre de 2000, de aplicación en España por virtud del Tratado de Lisboa de diciembre de 2007, constituye un precipitado de diferentes derechos ciudadanos, nada menos que de rango fundamental, que a lo largo del tiempo y a lo largo de los diferentes Ordenamientos han caracterizado la posición central que hoy tiene la ciudadanía en todo lo que se refiere al Derecho Administrativo. Hoy, en el siglo XXI, el ciudadano ya no es un sujeto inerte que simplemente recibe bienes y servicios públicos, sino que debe participar en la determinación del interés general, que ya no define unilateralmente la Administración pública pues como dice el Tribunal Constitucional en una sentencia de 7 de febrero de 1984, éste se define a través de una acción intercomunicada entre Poderes públicos y agentes sociales.

El citado artículo 41 de la Carta Europea dispone que:

"1. Toda persona tiene derecho a que las instituciones y órganos de la Unión traten sus asuntos imparcial y equitativamente y dentro de un plazo razonable.

2. Este derecho incluye en particular:

-el derecho de toda persona a ser oída antes de que se tome en contra suya una medida individual que le afecte desfavorablemente. 
-el derecho de toda persona a acceder al expediente que le afecte, dentro del respeto a los intereses legítimos de la confidencialidad y del secreto profesional y comercial.

-la obligación que incumbe a la Administración de motivar sus decisiones.

3. Toda persona tiene derecho a la reparación por la Comunidad de los daños causados por sus instituciones o sus agentes en el ejercicio de sus funciones, de conformidad con los principios generales comunes a los Derechos de los Estados miembros.

4. Toda persona podrá dirigirse a las instituciones de la Unión en una de las lenguas de los Tratados y deberá recibir una contestación en esa misma lengua”.

Los ciudadanos europeos tenemos un derecho fundamental a que los asuntos públicos se traten imparcialmente, equitativamente y en un tiempo razonable. Es decir, las instituciones comunitarias han de resolver los asuntos públicos objetivamente, han de procurar ser justas -equitativas- $y$, finalmente, han de tomar sus decisiones en tiempo razonable. En otras palabras, no cabe la subjetividad, no es posible la injusticia y no se puede caer en la dilación indebida para resolver.

La referencia la razonabilidad del plazo para resolver incorpora un elemento esencial: el tiempo. Si una resolución es imparcial, equitativa, pero se dicta con mucho retraso, es posible que no tenga sentido, que sea inútil. El poder público se mueve en las coordenadas del espacio y del tiempo y éste, el tiempo, es un elemento esencial. La razonabilidad se refiere al plazo de tiempo en el que la resolución pueda ser eficaz de manera que no se dilapide el legítimo derecho del ciudadano a que su petición, por ejemplo, se conteste en un plazo en que ya no sirva para nada.

El derecho a la buena administración es un derecho fundamental de todo ciudadano comunitario a que las resoluciones que dicten las instituciones europeas sean imparciales, equitativas y razonables en cuanto al fondo y al momento en que se produzcan. Dicho derecho según el citado artículo 41 incorpora, a su vez, cuatro derechos.

El primero se refiere al derecho a que todo ciudadano comunitario tiene a ser oído antes de que se tome en contra suya una medida individual que le afecte desfavorablemente. Se trata de un derecho que está reconocido en la generalidad de las legislaciones administrativas de los Estados miembros como consecuencia de la naturaleza contradictoria que tienen los procedimientos administrativos en general, y en especial los procedimientos administrativos sancionadores o aquellos procedimientos administrativos de limitación de derechos. Es, por ello, un componente del derecho a la buena administración que el Derecho Comunitario toma del Derecho Administrativo Interno.

El segundo derecho derivado de este derecho fundamental a la buena administración se refiere, de acuerdo con el párrafo segundo del citado artículo 41 de la Europea de Derechos Fundamentales, al derecho de toda persona a acceder al expediente que le afecte, dentro del respeto de los intereses legítimos de la confidencialidad y del secreto profesional y comercial. Nos encontramos, de nuevo, con otro derecho de los ciudadanos en los procedimientos administrativos generales. En el Derecho Administrativo Español, por 
ejemplo, este derecho al acceso al expediente está recogido dentro del catálogo de derechos que establece el artículo 35 de la ley del régimen jurídico de las Administraciones públicas y del procedimiento administrativo común de noviembre de 1992. Se trata, de un derecho subjetivo lógico y razonable que también se deriva de la condición que tiene la Administración pública, también la comunitaria, de estar al servicio objetivo de los intereses generales, lo que implica, también, que en aras de la objetividad y transparencia, los ciudadanos podamos consultar los expedientes administrativos que nos afecten. Claro está, existen límites derivados del derecho a la intimidad de otras personas así como del secreto profesional y comercial o de la seguridad pública, excepciones que habrán de interpretarse restrictivamente.

El tercer derecho que incluye el derecho fundamental a la buena administración es el derecho de los ciudadanos a que las decisiones administrativas de la Unión europea sean motivadas. Llama la atención que este derecho se refiere a todas las resoluciones europeas sin excepción. Que todas las decisiones de las Autoridades de la Unión Europea sean motivadas es la consecuencia de que el ejercicio del poder en las democracias debe ser argumentado, razonado, motivado por la sencilla razón de que el poder público debe realizarse de forma objetiva. El poder que se basa en la razón es legítimo. El que no se justifica es sencillamente arbitrario. Por eso todas las manifestaciones del poder público deben motivarse. La intensidad de la justificación dependerá de la naturaleza de los actos de poder. Si son reglados la motivación será menor. Pero si son discrecionales, la exigencia de motivación será mayor. Es tan importante la motivación de las resoluciones públicas que bien puede afirmarse que la temperatura democrática de una Administración es proporcional a la intensidad de la motivación de los actos y normas administrativas.

En una sentencia de 15 de octubre de 2010, el Tribunal Supremo del Reino de España precisa el alcance de la motivación que exige nuestra Constitución señalando que tal operación jurídica "se traduce en la exigencia de que los actos administrativos contengan una referencia específica y concreta de los hechos y los fundamentos de derecho que para el órgano administrativo que dicta la resolución han sido relevantes, que permita reconocer al administrado la razón fáctica y jurídica de la decisión administrativa, posibilitando el control judicial por los tribunales de lo contencioso administrativo". Además, tal obligación de la Administración "se engarza en el derecho de los ciudadanos a una buena administración, que es consustancial a las tradiciones constitucionales comunes de los Estados miembros de la Unión Europea, que ha logrado refrendo normativo como derecho fundamental en el artículo 41 de la Carta de los Derechos Fundamentales de la Unión Europea, proclamada por el Consejo de Niza de 8/10 de diciembre de 2000, al enunciar que este derecho incluye en particular la obligación que incumbe a la Administración de motivar sus decisiones".

En el apartado tercero del precepto se reconoce el derecho a la reparación de los daños ocasionados por la actuación u omisión de las instituciones comunitarias de acuerdo con los principios comunes generales a los Derechos de los Estados miembros. La obligación de indemnizar en los supuestos de responsabilidad contractual y extracontractual de la Administración está, pues, recogida en la Carta. Lógicamente, el correlato es el derecho a la consiguiente reparación cuándo las instituciones comunitarias incurran en responsabilidad. La peculiaridad del reconocimiento de este derecho, también fundamental, derivado del fundamental a la buena administración, reside en que el régimen de funcionalidad de este 
derecho se establecerá desde los principios generales de la responsabilidad administrativa en Derecho Comunitario.

El apartado cuarto dispone que toda persona podrá dirigirse a las instituciones de la Unión en una de las lenguas de los Tratados y deberá recibir una contestación en esa lengua.

\section{LA DIMENSIÓN ÉTICA DE LA FUNCIÓN PÚBLICA.}

La referencia ética de la función pública es una característica del quehacer público de especial relevancia. Los postulados de la recta razón, el deber especialmente, conforma la dimensión ética, también en la función pública. El ethos de la Administración pública española está previsto en el artículo 103 de la Constitución cuando dispone que la Administración pública está al servicio objetivo del interés general.

La Ética parte de la dignidad de la persona y aspira a que podamos vivir, todos los seres humanos, una vida auténticamente humana, también quienes trabajan al servicio de las Administraciones públicas. Desde muchos espacios se viene postulando la necesidad de una regeneración ética porque, como decía ORTEGA Y GASSET, una sociedad desmoralizada es aquella a la que falta el ánimo, el tono vital necesario para enfrentarse con gallardía a los retos que se presentan y, por el contrario, una sociedad sana es aquella a la que sobran arrestos para desafiar el destino respondiendo además con sensibilidad humana.

En los últimos tiempos, especialmente en este contexto de crisis, la Ética se ha puesto de moda, de palpitante y rabiosa actualidad. Los políticos y administradores promueven normas anticorrupción, los bancos impulsan Códigos éticos, los colegios profesionales refuerzan sus Comisiones Deontológicas; hasta los periodistas han tratado de los límites del derecho a la información... Es verdad, de un tiempo a esta parte la cuestión de la Ética concentra ríos de tinta en las redacciones de los medios de comunicación, escritos y tantas y tantas palabras en los noticiarios de las televisiones. Sin embargo, la percepción social no parece inclinarse hacia la existencia, sobre todo en los dirigentes públicos, de una mayor sensibilidad ética. Se habla, se debate, se conferencia, se diserta, se escribe pero, $\&$ se practica ?. Este es el gran tema porque, a la larga, lo que interesa, sobre todo, es que la Ética resplandezca en la vida de los seres humanos, sobre todo de quienes trabajan al servicio de las Administraciones públicas.

La Ética se apoya en la distinción entre lo que se puede hacer y lo que se debe hacer, porque, es un principio básico, no todo lo posible es ético, no todo lo que se puede hacer se debe hacer. Más bien se, debe hacer todo aquello, en el ámbito de la rectoría y dirección de los asuntos públicos, que implique promoción de los derechos de la persona, todo lo que traiga consigo el fortalecimiento de los valores democráticos, todo lo que suponga, en una palabra, seguir correcta y adecuadamente los dictados del servicio objetivo al interés general. 
En este marco, han surgido estudios y análisis científicos sobre la Ética Pública porque se percibe su necesidad y porque los ciudadanos exigen cada vez servicios de responsabilidad pública de mayor calidad, más universales, de más calidad y más asequibles. Asimismo, los ciudadanos esperan un trato más adecuado de los servicios públicos en los que brille con luz propia la vocación de servicio que debe ser señal indeleble del funcionamiento y actividad de todos los servicios y, sobre todo, de las personas que en ellos laboran.

El renacimiento del interés por la ética se produjo concretamente en el mundo de los negocios y de la empresa privada hace tres o cuatro décadas, teniendo como resultado el desarrollo, es cierto que todavía no muy logrado, de nuevas sensibilidades sociales en las empresas que transcienden de lo puramente económico. La aplicación de esta reflexión ética a la Administración Pública es mucho más tardía, habiéndose fijado su nacimiento en 1978, fecha de publicación del primer libro sobre el tema ("Ethics for bureaucrats" de John ROHR).

La Administración Pública del Estado social y democrático de Derecho es una organización que debe distinguirse por los principios de juridicidad, de eficacia y de servicio. Juridicidad porque el procedimiento administrativo no es otra cosa que un camino pensado para salvaguardar los derechos e intereses legítimos de los ciudadanos. Eficacia porque hoy es perfectamente exigible a la organización administrativa que ofrezca productos y servicios públicos de calidad. Y servicio, sobre todo, porque no se puede olvidar que la justificación de la existencia de la Administración se encuentra en el servicio a los intereses colectivos, en el servicio del bien común. Por eso, una de las asignaturas pendientes de la Administración pública de nuestro tiempo es la recuperación de la idea de servicio y, eso sí, la necesaria profesionalización de la Administración pública que, en cualquier caso, ha de estar, no sólo abierta a la sociedad, sino pendiente ante las demandas colectivas para ofrecer servicios públicos de calidad.

La Ética pública estudia el comportamiento del personal al servicio de las Administraciones públicas en orden a la finalidad del servicio público que le es inherente. Es la Ciencia que trata de la moralidad de los actos humanos en cuanto realizados por personal al servicio de las Administraciones públicas. La Ética pública es, como la Ética en sí misma, una ciencia práctica. Es ciencia porque el estudio de la Ética para la Administración pública incluye principios generales y universales sobre la moralidad de los actos humanos realizados por las personas al servicio de las Administraciones públicas. Y es práctica porque se ocupa fundamentalmente de la conducta libre del hombre que desempeña una función pública, proporcionándole las normas y criterios necesarios para actuar bien.

En un Estado social y democrático de Derecho, la Administración ya no es dueña del interés general sino que está llamada a articular una adecuada intercomunicación con los agentes sociales para definir las políticas públicas. Desde esta perspectiva puede entenderse mejor la función promocional de los poderes públicos, cuya misión es crear un ambiente en el que los ciudadanos puedan ejercer sus derechos fundamentales y colaborar con la propia Administración en la gestión de los intereses públicos. En este contexto, el aparato público debe ofrecer servicios de calidad y promocionar los derechos fundamentales de los ciudadanos. 
Los principios de la Ética pública deben ser positivos y capaces de atraer al servicio público a personas con vocación para gestionar lo del común, lo de todos. He aquí algunos de ellos.

En primer lugar, los procesos selectivos para el ingreso en la función pública deben estar anclados en el principio del mérito y la capacidad. Y no sólo el ingreso sino la carrera administrativa.

En segundo lugar, la formación continuada que se debe proporcionar al personal al servicio de las Administraciones públicas ha de ir dirigida a transmitir la idea de que el trabajo al servicio del sector público debe realizarse adecuadamente pues se la Constitución exige que las actuaciones de las Administraciones públicas se sometan al servicio objetivo del interés general.

En tercer lugar, la llamada gestión de personal y las relaciones humanas en la Administración pública deben estar presididas por una buena educación. El clima y el ambiente laboral han de ser positivos y el personal al servicio de las Administraciones públicas debe esforzarse por vivir cotidianamente ese espíritu de servicio a la colectividad que justifica la propia existencia de la Administración pública.

En cuarto lugar, la actitud de servicio objetivo al interés general debe ser el elemento más importante de esta cultura administrativa. La mentalidad y el talante de servicio se encuentran en la raíz de todas las consideraciones sobre la Ética Pública y explica, por sí mismo, la importancia del trabajo administrativo.

En quinto lugar, debe destacarse que constituye un importante valor deontológico potenciar el sano orgullo que trae consigo la identificación del personal con los fines del organismo público en el que trabaja. Se trata de la lealtad institucional, que constituye un elemento capital y una obligación central de una gestión pública que aspira al mantenimiento de comportamientos éticos.

En sexto lugar, conviene señalar que la formación en Ética pública debe ser un ingrediente imprescindible en los Planes de Formación para funcionarios públicos. Además, deben buscarse fórmulas educativas que hagan posible que esta disciplina se imparta en los programas docentes previos al acceso a la función pública. Y, por supuesto, debe estar presente en la formación continua del personal al servicio de las Administraciones públicas.

En séptimo lugar, el personal al servicio de la Administración pública debe tender a trabajar de acuerdo con las fórmulas más eficientes y económicas, siempre en un contexto de servicio y equidad, para llevar a cabo su tarea.

En octavo lugar, la actuación pública debe estar guiada por los principios de igualdad y no discriminación.

En noveno lugar, el personal debe actuar siempre como servidor público y no debe transmitir información privilegiada o confidencial. 
En décimo y último lugar, el interés general en el Estado social y democrático de Derecho se encuentra en facilitar a los ciudadanos un conjunto de condiciones que haga posible el ejercicio de la libertad solidaria y les permitan un ejercicio efectivo de todos sus derechos fundamentales. Por tanto, los funcionarios deben ser conscientes de esa función promocional de los poderes públicos y actuar en consecuencia.

\section{CÓDIGOS DE BUEN GOBIERNO.}

En 1981, la Asociación Internacional de Escuelas e Institutos de Administración pública recomendó reforzar la codificación los criterios éticos del servicio público y, por ello, el buen gobierno y la buena administración de lo público. Las razones de tal decisión se encuentran en que en un mundo complejo como el actual, la gestión de los intereses generales ofrece numerosos dilemas éticos que deben resolverse en el marco de los principios de buena administración y de buen gobierno, inspirados en última instancia en que los gestores y administradores ejercen poderes y potestades en nombre y representación de los ciudadanos y a ellos deben dar cuentas de tal encargo permanentemente y motivadamente.

En efecto, no sólo es necesaria la competencia y los conocimientos, hace falta que esos conocimientos, que siempre son un medio, se utilicen para hacer realizar el servicio objetivo al interés general. Por eso, en su trabajo diario el personal al servicio de las Administraciones públicas debe seguir los dictados del servicio objetivo al interés general. Las personas que laboran en la Administración pública no son insensibles elementos de un aparato administrativo que mecánicamente está orientado al interés general. Son servidores públicos involucrados, especialmente los directivos, en el ejercicio objetivo del poder público y están obligados a definir objetivos sociales, a configurar políticas públicas o a seleccionar información Es decir, deben ejercitar juicios éticos con mucha frecuencia y, por ello, parece aconsejable que dispongan de un marco que oriente la acción, en el que se establezcan con claridad los criterios rectores del servicio público, que nuestra Constitución resume en el servicio objetivo al interés general.

La codificación de principios y reglas éticas para el servicio público y para el buen gobierno y la buena administración es una tarea necesaria que ayuda a recuperar los valores de lo público. Tal codificación debe tener presente la naturaleza del trabajo concreto que realizan las personas al servicio de las Administraciones públicas así como las exigencias de los ciudadanos, que disponen de un derecho a una buena Administración pública y que, por tanto, pueden y deben reaccionar jurídicamente ante la lesión de tal derecho fundamental.

En la elaboración de los Códigos de Ética pública y Buen Gobierno deben conjugarse elementos de diversa naturaleza, pues además de orientar y promover conductas éticas en la labor del personal al servicio de las Administraciones públicas, éstas deben articularse en sintonía con la protección de los derechos individuales de los propios empleados públicos. Así, por ejemplo, en el Código canadiense los funcionarios deben gozar en sus actividades privadas de los mismos derechos que cualquier otro ciudadano salvo que su limitación venga aconsejada por motivos de interés general. Del mismo modo, el Código australiano dispone, 
en relación con estos derechos, que "cuando el comportamiento personal no interfiere en el cumplimiento correcto de sus obligaciones oficiales $\mathrm{y}$, cuando no perjudica a la integridad o prestigio del servicio público, no es de interés ni concierne al organismo en el que el funcionario presta sus servicios". Es decir, los Códigos de Ética pública Buen Gobierno, aunque limiten la actividad de los funcionarios, en realidad refuerzan su talante de servidores públicos vinculados por el servicio objetivo al interés general en el marco del Estado social y democrático de Derecho.

Las normas escritas permiten conocer con objetividad los criterios de actuación del personal al servicio de las Administraciones públicas. Y, de otra parte, proporcionan un importante mecanismo para la resolución de conflictos. Además, la existencia de un conjunto de normas éticas escritas impedirán, o al menos harán más difícil, la corrupción en cualquiera de sus diferentes modalidades. Por otra parte, en muchos casos el Código puede servir al personal al servicio de las Administraciones públicas para rechazar formalmente determinadas propuestas incompatibles con el servicio objetivo al interés general. También la codificación permite que los directivos puedan exigir responsabilidades a los empleados públicos por sus actuaciones.

En Norteamérica, la mitad de los Estados disponen de textos legales de Ética y Buen Gobierno. Por su parte, el Gobierno federal de EEUU desde 1978 cuenta con la Ley de Ética en la Administración pública. Esta norma codificó y completó la legislación anterior y creó en la nueva Oficina de Gestión de Personal una Oficina de Ética de Administración para seguir el cumplimiento de esta normativa.

En Canadá el Código de Ética y Buen Gobierno es de naturaleza general ya que cualquier intento de identificar todos los posibles conflictos no es posible y requeriría una revisión e interpretación constante. Por ello, se ha preferido sentar principios generales claros y las situaciones concretas se analizarán en función de los principios. Además, el Código sugiere que los propios departamentos y agencias completen los principios o directrices con prescripciones más específicas relacionadas con sus propias necesidades.

Los Códigos de Ética y Buen Gobierno pueden ser clasificados en generales y concretos. El prototipo de los generalistas, como señala KERNAGHAN serían "Los Diez Mandamientos", mientras que el representante de los Códigos detallados seria el Código de Justiniano. En este sentido, las diez clausulas breves y generales del Código de Ética para el servicio gubernamental de los Estados Unidos que fue establecido en 1958. Por el contrario, el Código de Justiniano es un largo documento que proporciona información comprensiva de los posibles conflictos éticos y, además, castiga las conductas anti-éticas. En esta línea, por ejemplo, el Código del Australian Public Service Board contiene seis capítulos en el que se concreta ampliamente las conductas anti-éticas y sus consecuencias.

Los Códigos no resuelven por sí mismos todos los problemas y dilemas éticos pero son puntos de referencia importantes y permiten que los valores del servicio público se encuentren escritos y al alcance, no solo del personal al servicio de la Administración pública, sino también de los ciudadanos. 
La American Society of Public Administration (ASPA) ha elaborado un Código general de Ética y Buen Gobierno para la Administración pública. Se trata de un código que se refiere especialmente a la importancia de la responsabilidad individual del personal al servicio de la Administración pública y que diseña unos principios a los que los funcionarios orienten su comportamiento en la actividad administrativa. Esta necesaria codificación parte de la teoría de la agencia. Es decir, quienes laboran en la Administración pública deben preocuparse de buscar los objetivos de la propia organización administrativa antes que los fines personales. Tal compromiso debe realizarse en un marco de normas generales de justicia universal y de acuerdo con que la agencia representa a los ciudadanos y se entiende que el personal al servicio de las Administraciones públicas tiene claro que su actividad se fundamenta sobre todo en que hacen un trabajo precisamente en servicio de la colectividad.

\section{EL CÓDIGO EUROPEO DE BUENA CONDUCTA ADMINISTRATIVA}

El Código de Buena Conducta Administrativa de la UE, dirigido a las instituciones y a los órganos de la Unión Europea, aprobado por resolución del Parlamento Europeo de 6 de septiembre de 2001, es el instrumento de concreción del derecho fundamental a la buena administración establecido en el artículo 41 de la Carta Europea de los Derechos Fundamentales de diciembre de 2000. En efecto, el Código dispone en la introducción, al final del epígrafe titulado naturaleza jurídica, que pretende concretar en la práctica el derecho a una buena administración establecido en la Carta Europea.

El Código señala en su artículo 1 que las instituciones y órganos de la UE deben respetar los principios establecidos en el Código en sus relaciones con el público. El Código es de aplicación, artículo 2, a todos los funcionarios y agentes de la UE de acuerdo con el Estatuto de la función pública europea y el régimen jurídico aplicable a los agentes de la Unión. El Código precisa, en el artículo 2, que entiende por público a toda persona física o jurídica, independientemente de que residan o tengan su domicilio en un Estado miembro.

Por lo que se refiere al ámbito material de aplicación, el Código contiene los principios generales de buena administración aplicables a todas las relaciones entre las instituciones y el público. En el artículo 4 dispone que el funcionario actuará de conformidad con la legislación y aplicará las normas y procedimientos establecidos en la legislación comunitaria. En concreto, el funcionario velará porque las disposiciones que afecten a los derechos o intereses de los ciudadanos estén basados en la ley y que su contenido cumpla la legislación. En el artículo 5 empiezan las referencias a los principios generales de buena conducta administrativa, que constituyen el corolario necesario del derecho fundamental a la buena administración del que disponen los ciudadanos de la UE. El primero de estos principios generales es el de igualdad o, en términos negativos, ausencia de discriminación. El principio se plantea en el marco de la tramitación de las solicitudes del público y en el ámbito de la toma de decisiones. En ambos casos, el funcionario debe garantizar el principio de igualdad de trato, que implica que los ciudadanos que se encuentren en la misma situación 
procedimental serán tratados de igual manera, de manera similar dice el Código. En el caso de que se produzca alguna diferencia de trato, está deberá ser justificada, motivada convenientemente en función, dice el Código, de las características pertinentes objetivas del caso. Es decir, la motivación debe estar fundada sobre la realidad, sobre las características pertinentes del caso y, lo que es más importante, debe hacerse objetivamente.

El contenido del principio de ausencia de discriminación, en particular, implica que el funcionario evitará toda discriminación injustificada entre miembros del público por razones de nacionalidad, sexo, raza, color, origen étnico o social, características genéticas, lengua, religión o creencias, opiniones políticas o de cualquier tipo, pertenencia a una minoría nacional, propiedad, nacimiento, discapacidad, edad u orientación sexual.

El Código se refiere en su artículo 6 al principio de proporcionalidad: al adoptar decisiones el funcionario garantizará que las medidas sean proporcionales al fin perseguido, evitando toda forma de restricción de los derechos de los ciudadanos así como la imposición de cargas cuándo éstas y aquellas no sean razonables con respeto al objeto perseguido. Además, al adoptar decisiones, el funcionario respetará el justo equilibrio entre los intereses individuales y el interés público general.

El poder en el Estado de Derecho sólo tiene sentido se ejerce al servicio objetivo del interés general. Por eso, el artículo 7 se refiere al principio de ausencia de abuso de poder y a que los poderes se ejercerán únicamente de acuerdo con la finalidad para la que han sido otorgados por las disposiciones pertinentes, evitando el uso de dichas potestades para objetivos sin fundamento legal o que no estén motivados por un interés público. La imparcialidad y la independencia son también dos principios básicos que deben distinguir la actuación de los funcionarios comunitarios y, por ende, a las mismas instituciones europeas. En virtud de la imparcialidad, dice el artículo 8 que el funcionario se abstendrá de toda acción arbitraria que afecte adversamente a los ciudadanos, así como de cualquier trato preferente por cualesquiera motivos. A la independencia de los funcionarios se refiere el artículo 8 en su último parágrafo en estos términos: "la conducta del funcionario nunca estará guiada por intereses personales, familiares o nacionales, ni por presiones políticas. El funcionario no participará en una decisión en la que el mismo, o un familiar cercano, tenga intereses económicos".

El principio de objetividad en el Código está redactado, artículo 9, en términos de principio de relevancia, que es una consecuencia concreta de la objetividad: "al adoptar sus decisiones, el funcionario tendrá en cuenta los factores relevantes y otorgará a cada uno de los mismos su propia importancia en la decisión, excluyendo de su consideración todo elemento irrelevante".

El artículo 10 del Código señala que el funcionario será coherente en su propia práctica administrativa, así como en la actuación administrativa de la institución, lo que implica que el funcionario debe respetar el precedente administrativo existente en la institución, salvo que existan razones fundadas, en cuyo caso deberá, dice el artículo citado, expresar ese fundamento por escrito. El principio de confianza legítima está contemplado también en este precepto, concretamente en el párrafo segundo: "el funcionario respetará las legítimas y razonables expectativas de sus actuaciones ante los ciudadanos. El límite de este 
principio se encuentra en la legitimidad y la racionalidad de las expectativas generadas. Si éstas fueran ilegales o arbitrarias, nos encontraríamos con una grave lesión de este principio, que el Código denomina "legítimas expectativas, consistencia y asesoramiento".

Consecuencia de la equidad que el artículo 41 de la Carta exige a los funcionarios y a las instituciones en el principio de justicia, establecido en el artículo 11:"el funcionario actuará de manera imparcial, justa y razonable". El artículo 12 trata del principio denominado de cortesía, principio que es tratado en un sentido muy amplio, pues bajo la rúbrica general de cortesía, se hace referencia a la diligencia, a la corrección y a la accesibilidad a los ciudadanos. En este punto, el autor del Código ubica el deber de respuesta, que es una obligación, legal por supuesto, pero que tiene un fuerte contenido ético. Así, podemos leer en el párrafo primero de este artículo 12 que al responder a la correspondencia, llamadas telefónicas y correo electrónico, el funcionario tratará en la mayor medida posible de ser servicial y responderá a las preguntas que se le plantean de la manera más completa y exacta posible.

Una consecuencia del principio de servicio es que al ciudadano deben ahorrársele todos los trámites innecesarios. El párrafo segundo del artículo 12 dispone que si el funcionario advierte que un asunto sometido a su consideración no es de su competencia, deberá orientar al ciudadano en cuestión al funcionario realmente competente. En caso de que el funcionario incurra en error, el artículo señala que el funcionario presentará sus excusas, tratará de corregir los efectos negativos resultantes de su error de la forma más rápida posible e informará al interesado de las posibilidades de recurso de conformidad con el artículo 19 del código.

El Código garantiza que los ciudadanos que se dirijan a las instituciones comunitarias en una de las lenguas del Tratado recibirán una respuesta en dicha lengua (artículo 13). En este mismo sentido, de facilitar a los ciudadanos los trámites ante la UE, el artículo 14 del Código dispone que de toda reclamación o petición de los ciudadanos ante las instituciones de la UE se entregará a dichos ciudadanos un acuse de recibo en un plazo máximo de dos semanas, salvo que en este plazo se pueda enviar una contestación pertinente o salvo en los casos en los que las reclamaciones o peticiones resulten impertinentes, bien por su número excesivo o por ser repetitivas o absurdas. El acuse de recibo, señala el párrafo segundo del artículo 14, especificará el nombre y número de teléfono del funcionario competente para tramitar el asunto así como del servicio al que dicho funcionario pertenece.

El principio de servicio al ciudadano y de facilitación de los trámites se concreta en el artículo 15 del Código, en el que se establece que si un escrito o reclamación es dirigida a una institución que no sea competente para su tramitación, dicha unidad deberá ponerla en conocimiento del órgano competente advirtiendo de tal circunstancia al ciudadano solicitante indicándole además la identidad y el teléfono del funcionario competente al que se ha hecho llegar el expediente. Una vez que el funcionario competente empiece la instrucción del expediente deberá, en caso de existir errores u omisiones en la solicitud, comunicarlo al interesado facilitándole que pueda subsanar dichos errores u omisiones.

El derecho de audiencia y de hacer observaciones durante el procedimiento se encuentra reconocido en el artículo 16 del Código. El funcionario deberá garantizar este 
derecho, facilitando, además, que se respeten los derechos de defensa del interesado porque en el procedimiento administrativo, como señalamos con anterioridad, rige el derecho a la tutela administrativa efectiva. El derecho de audiencia se complementa con el derecho que asiste a todo ciudadano interesado en el procedimiento administrativo, siempre que la decisión afecte a sus derechos e intereses, de hacer observaciones y comentarios por escrito y, de ser necesario, a formular observaciones orales con anterioridad a la adopción de la decisión administrativa.

El derecho a la buena administración del artículo 41 de la Carta Europea de los Derechos Fundamentales incluye el derecho a que las decisiones se adopten en plazo razonable. Por eso, el artículo 17 del Código reconoce este derecho a la decisión en plazo razonable, sin demoras y, en caso de ser necesario, antes de un período de dos años a contar desde el momento en el que conste la recepción del escrito de solicitud. Este mismo derecho, sigue diciendo el precepto, se aplica también a la respuesta a cartas de los ciudadanos dirigidas a las instituciones comunitarias así como a las respuestas a notas administrativas que el funcionario haya enviado a sus superiores jerárquicos solicitando instrucciones relativas a las decisiones que deban adoptar. En el parágrafo segundo del artículo se contemplan los casos de expedientes complejos en los que no sea posible resolver en el plazo anteriormente indicado. En estos casos, el Código dispone que el funcionario competente informe al ciudadano autor del escrito en el más breve plazo de tiempo posible, significando que en estos casos la decisión administrativa deberá comunicarse a dicho ciudadano en el plazo más breve posible.

El derecho a la buena administración del artículo 41 de la Carta incluye la obligación para los funcionarios de motivar sus decisiones. Este derecho-deber a la motivación de las decisiones está regulado en el artículo 18. En este precepto se señala que toda decisión de las instituciones de la UE que pueda afectar desfavorablemente a los derechos e intereses de los ciudadanos deberá indicar los motivos en que esté basada, exponiendo claramente los hechos pertinentes y el fundamento jurídico de la decisión. En este sentido, el funcionario, según dispone el párrafo segundo del artículo, evitará adoptar decisiones basadas en motivos breves o genéricos que no contengan un razonamiento concreto. Es decir, la motivación de ser clara, concreta y con expresa referencia al supuesto individual al que se refiere. Cuándo las decisiones afecten a un número elevado de ciudadanos, según el parágrafo tercero del artículo 18, y no sea, por tanto, posible comunicar detalladamente los motivos de la decisión, se procederá a partir de respuestas normalizadas aunque el funcionario, en un momento posterior, facilitará al ciudadano que expresamente lo solicite una motivación individual.

El principio de servicio a los ciudadanos incluye, es lógico, que se les facilita la información relativa a los recursos y reclamaciones, con mención de las autoridades ante las que se deben presentar así como los plazos para hacerlo, que están a su disposición frente a las resoluciones administrativas que afecten desfavorablemente a los derechos e intereses de los ciudadanos, tal y como dispone el artículo 19 del Código.

Las notificaciones de las decisiones que afecten desfavorablemente a los derechos e intereses de los ciudadanos deberán ser comunicadas inmediatamente a su adopción, absteniéndose el funcionario de comunicar dichas resoluciones a otras fuentes antes que al ciudadano afectado, tal y como prescribe el artículo 20. 
El artículo 21 establece el principio del respeto a la vida privada y a la integridad de las personas, a la protección de los datos personales con ocasión de los procedimientos y decisiones administrativas, materia en la que se han de observar las normas comunitarias dictadas al efecto, evitando el funcionario especialmente el tratamiento de datos personales con fines no justificados o la transmisión de tales datos a personas no autorizadas.

El acceso a la información es otra manifestación del principio y del derecho a la buena administración. Tal materia ocupa el artículo 22 del Código, que impone a los funcionarios el deber de facilitar a los ciudadanos la información que soliciten, incluida la información acerca de cómo iniciar un procedimiento en el ámbito de su competencia. Por supuesto, la información suministrada por el funcionario debe ser clara y comprensible. Si la información se solicita oralmente y es demasiado complicada o demasiado extensa, el funcionario, párrafo segundo del artículo 22, indicará a la persona afectada que formule la petición por escrito. En caso de que la materia objeto de la información sea confidencial, el funcionario, párrafo tercero, deberá indicar al peticionario los motivos por los que no puede comunicar dicha información. Cuándo se soliciten informaciones de las que no sea competente el funcionario que reciba tales peticiones, deberá indicar al solicitante de las mismas el nombre y teléfono del funcionario competente $\mathrm{y}$, si fuera el caso, los datos de la institución competente o responsable para tratar dicha información (párrafo cuarto). Finalmente, el funcionario, dependiendo del tema de la solicitud, dirigirá a la persona solicitante de la información al servicio de información al público de la institución competente (párrafo quinto). El principio de servicio y de facilitación aconsejaría en este supuesto que sea el propio funcionario el que internamente haga llegar la solicitud de información a dónde corresponda, comunicando dicha circunstancia al solicitante.

En el mismo sentido, el artículo 23 se refiere al acceso de los ciudadanos a los documentos y archivos administrativos, señalando que en estos casos, dichas solicitudes se tratarán de acuerdo con el derecho comunitario.

El derecho de acceso a la información sólo será efectivo si los archivos en los que obran las informaciones están ordenados y bien tratados. Por eso el artículo 24 manda a los departamentos de las instituciones a mantener los adecuados archivos de correspondencia de entrada y salida de los documentos que reciban y de las medidas que se adopten.

Finalmente, cada institución procurará informar a los ciudadanos de sus derechos y, cuándo sea posible, lo hará electrónicamente, publicándolo en su página web. Además, la propia Comisión europea, en nombre de todas las instituciones de la UE publicará y distribuirá el Código entre los ciudadanos en forma de folleto (artículo 25).

El Defensor del pueblo Europeo es la institución competente para conocer de las reclamaciones frente a lesiones o incumplimientos establecidos en este Código dice el artículo 26, por lo que adquiere una gran relevancia en orden a la garantía del derecho a la buena administración y a la preservación de los principios éticos de la función pública en Europa. 


\section{REFLEXIÓN CONCLUSIVA}

La democracia ha vencido, la que tenemos es la única democracia real que se ha realizado sobre la tierra: la democracia liberal. Estas palabras de Giovanni SARTORI nos ayudan a entender el sentido de los principios sobre los que asienta la democracia liberal: separación de poderes, reconocimiento de los derechos fundamentales de la persona y primacía del principio de legalidad. La separación de poderes hoy se ha convertido, en tantos países, en una quimera, en un sueño, debido a que la preponderancia de los partidos ha terminado por impedir que cada poder cumpla autónomamente su función. El reconocimiento de los derechos fundamentales también es desconocido cuándo se impide la igualdad de todos ante la ley pues los fuertes se la saltan con frecuencia mientras a los débiles e inocentes se les aplica rigurosamente. Y no digamos el principio de legalidad, conculcado cuándo al poder dominante no le viene bien alguno de los preceptos de la ley o de la Constitución; entonces, en ejercicio del uso alternativo del mando, se viola sin más, arrumbando cientos de años de lucha por racionalizar y limitar aquel absolutismo y autoritarismo entonces tan denostado, que hoy, siquiera sea sutilmente, vuelve a asomar desde dentro del sistema.

Alain TOURAINE definió la democracia como el conjunto de garantías institucionales que permiten combinar la unidad de la razón instrumental con la diversidad de las minorías. Ahora bien, es probable que la razón iluminada por la justicia, expresión real de la democracia, no entienda bien la dictadura de las minorías a que nos está conduciendo la forma de permanecer en el poder a cualquier precio que caracteriza a nuestros actuales dirigentes.

Los ciudadanos queremos que se trabaje por el entendimiento y que los dirigentes tengan la grandeza y la altura de miras suficiente para mirar al futuro con ilusión. Si así no lo hacen, el pueblo, cuándo toque, actuará en consecuencia. Porque, como escribió G.W. SAHW, la democracia es el proceso que garantiza que no seamos gobernados mejor de lo que nos merecemos.

En este contexto, es menester abrir la democracia a la vitalidad del pueblo, despejando esos siniestros vericuetos por los que aspiran a transitar tantos especialistas de un interés general que sigue contemplándose como algo cerrado y estático. Como algo de la propiedad de los dirigentes cuando en realidad el verdadero dueño y señor del espacio público es el pueblo. Así de claro.

Seguramente, una de las cuestiones que más preocupa a los teóricos de la política es la incidencia del mercado o del Estado, en la democracia. El Estado abierto y plural al que aspiramos va quedando atrás mientras se nos gobierna, cada vez más perceptiblemente, desde esquemas de pensamiento único alejados de las preocupaciones reales de la ciudadanía en un intento, suave en las formas pero radical en su contenido, de un nuevo intervencionismo que busca el control social y la perpetuación en el poder.

Por lo que se refiere al mercado, tendríamos que empezar reconociendo que es fundamental la existencia de posibilidades de elección lo que, al menos teóricamente, garantiza un sistema de intercambios voluntarios. El problema es que el mercado no es la 
fuente de los derechos ni esa panacea que todo lo resuelve. Es, como acaba de señalar Amartya SEN, una institución más entre un buen puñado de ellas, importante, por supuesto, pero ni la única institución relevante ni, por supuesto, la más importante. En este contexto, hemos de tener presente la aspiración a la democracia global que supone, entre otras cosas, la existencia de espacios mundiales de deliberación pública en los que a través de la racionalidad se pueda influir para que las versiones del pensamiento único, tanto del mercado como del Estado, den paso a perspectivas más plurales y más solidarias.

Promover el razonamiento público crítico es cada vez más relevante si es que de verdad queremos que las decisiones políticas y económicas sean cada vez más justas y solidarias. Es más, gracias a la emergencia de nuevas formas de reflexión y de pensamiento abierto y crítico orientadas a fortalecer la democracia, instituciones multilaterales del orden internacional han debido ir, poco a poco, modificando alguna de sus políticas económicas, lo que años atrás era, sencillamente, impensable.

La libertad de prensa juega un gran papel en la creación de un espacio abierto y libre de deliberación pública a nivel mundial. Junto a ella, las nuevas posibilidades que hoy ofrecen las nuevas tecnologías, están propiciando un escenario para el debate en numerosas weblog, que permiten aflorar opiniones y puntos de vista que no tienen acceso a los medios tradicionales de comunicación, quizás por no someterse a los dictados del pensamiento único, al pensamiento política y eficazmente correcto.

Hoy cada vez está más cerca la posibilidad de que todas las personas que quieran contribuir a que la globalización sea más justa y equitativa, puedan hacerlo. La clave está en que los que toman las decisiones sean más partidarios del pensamiento plural, abierto y compatible y estén menos presos de esa obsesión por el dinero, el poder, el placer o la notoriedad. Tres locomotoras en las que hoy se han instalado decenas de miles de personas que se han olvidado del pensamiento abierto, del pensamiento crítico, $\mathrm{y}$, sobre todo, del sentido y finalidad de la política: mejorar las condiciones de vida de las personas y fomentar el libre y solidario desarrollo de cada uno de los derechos fundamentales.

\section{BIBLIOGRAFIA}

RISTÓTELES, Etica a Nicómaco, Medina y Navarro editores, Madrid, 1873

C.J. BONNIN, Principios de Administración pública, Fondo de Cultura Económica, México, 2004.

M. CROZIER, El fenómeno burocrático, Amorrortu, Bilbao, 1974.

G. FERNÁNDEZ FARRERES, Los códigos de buen gobierno en las administraciones públicas, Administración y ciudadanía Vol. 2, nº 2, 2010.

F. GARRIDO FALLA, Tratado de Derecho Administrativo, Tecnos, Madrid, 2005 
E. GARCIA DE ENTERRÍA, con TR FERNANDEZ, Curso de Derecho Administrativo, Civitas, Madrid, 2011

E. GARCÍA DE ENTERRÍA, La significación de las libertades públicas para el Derecho Administrativo, Anuario de Derechos Humanos, Universidad Complutense de Madrid, 1981.

F. GONZÁLEZ NAVARRO, Derecho Administrativo Español, Eunsa, Navarra, 1994

J. HABERMAS, Teoría de la acción comunicativa, Paidós Ibérica, Barcelona, 2000

J. HABERMAS, Aclaraciones a la ética del discurso, Trotta, Madrid, 2000.

D. HUME, Historia natural de las religiones, Tecnos, Madrid, 1992

A. LLANO, Humanismo cívico, Ariel, Barcelona, 1999

O. MIR PUIG-PELAT, La responsabilidad patrimonial de la Administración pública, Civitas, Madrid, 2002

L. MEMBIELA, La buena administración en la Administración general del Estado, Actualidad administrativa, $\mathrm{n}^{\circ} 4,2007$

J.A. MORENO MOLINA, y J.M. MAGÁN, La responsabilidad patrimonial de las Administraciones públicas, El consultor, Madrid, 2005.

A. NIETO, Corrupción en la España contemporánea, Ariel, Barcelona, 1997.

M.J. PARDO, De la Administración pública a la gobernanza, Colegio de México, México, 2004.

R. PARADA, Derecho Administrativo, Marcial Pons, Madrid, 2007

J. RIFKIN, La sociedad empática, Paidós Ibérica, Barcelona, 2010.

J. RODRÍGUEZ-ARANA, El poder público y el ciudadano: la buena Administración pública como principio y como derecho, Madrid, 2012

B. TOMÁS MALLÉN, El derecho fundamental a la buena administración, INAP, Madrid, 2004.

M. VILLORIA, La corrupción política, Síntesis, Madrid, 2007.

R. VON IHERING, La lucha por el derecho, Comares, Granada, 2008

M. WEBER, La ética protestante y el espíritu del capitalismo, Alianza Editorial, Madrid, 2001 